\title{
SOBRE LA HISTORIA, EL PAISAJE Y SU POSIBLE INFLUENCIA EN EL TOPÓNIMO DE BARRAX
}

\section{ON THE HISTORY, THE LANDSCAPE AND ITS POSSIBLE IN- FLUENCE ON THE BARRAX TOPONYM}

\author{
ElVIRA VAlero De LA Rosa \\ Archivo Histórico Provincial de Albacete \\ Albacete, JCCM, España \\ evalero@jccm.es
}

Cómo citar este artículo: Valero de la Rosa, E. (2021). Sobre la historia, el paisaje y su posible influencia en el topónimo de Barrax.. Al-Basit (66), 463-469. http:// doi.org/10.37927/al-basit.66_12

Recibido/Received: 04-10-2021

Aceptado/Accepted: 25-10-2021

RESUMEN: el presente artículo analiza el topónimo de Barrax desde las aportaciones que la Historia y los documentos de los archivos proporcionan.

PALABRAS CLAVE: toponimia, Barrax, archivos.

\begin{abstract}
This article analyzes the toponym of Barrax from the contributions that History and the documents of the archives provide.
\end{abstract}

KEYWORDS: toponymy, Barrax, archives.

\section{INTRODUCCIÓN}

La toponimia es una ciencia interdisciplinar en la que intervienen distintas ramas como la Lingüística Histórica, la Lingüística Comparada o la Dialectología, pero también la Historia, la Arqueología, la Geografía, la Topografía, la Botánica y otras ciencias naturales (García, 2007, p. 16). Atendiendo a esta característica nos permitimos incursionar en una ciencia tan compleja como la toponimia y aportar el significado que proporciona el análisis pormenorizado de la documentación de nuestros archivos sobre el topónimo de Barrax. Creemos que la propia historia de la población, su entorno 
y el aprovechamiento natural de sus recursos constituyen la base sobre la que se forjó su nombre. Es lo que García Sánchez denomina motivación referencial, que aúna no sólo el paisaje, sino también la actividad del hombre en su entorno (2007, pp. 20-21).

Entre los conjuntos referenciales más importantes se encuentran el oronímico, hidronímico y fitonímico, porque los accidentes del terreno, los cursos del agua y la vegetación se tomaron por unánime contemplación visual como nombres consustanciales con lo percibido. Como ejemplos próximos y sencillos podemos citar Albacete (del árabe al-bas ìt 'la llanura') ${ }^{1}$, Fontanar, Fuenfría, o El Robledo (Pocklington, 2010). Además, hemos de tener en cuenta que las poblaciones actuales fueron en origen núcleos rurales o lugares deshabitados con un paisaje completamente distinto al de hoy y que recibieron su nombre en función de las referencias que mejor las identificaban (García, 2007, pp. 20-21).

Comencemos por la referencia histórica. Para remontarnos al origen de Barrax debemos retroceder hasta finales del siglo XIII o principios del XIV y a las medidas repobladoras que don Juan Manuel llevó a cabo en su tierra del señorío de Villena, de la que se hizo cargo desde 1294, impulsando la agricultura en inmensos despoblados como lo era Barrax. En el caso que nos ocupa es necesario aclarar que lo que se conocía en aquella época como «campo de Barrax» no se correspondía con el término municipal actual, sino que era una amplia extensión de tierra sin cultivar. Esta circunstancia propició que el infante don Juan Manuel hiciera donaciones de tierras en varios parajes que en aquel momento pertenecían a Chinchilla como Casa Alcaide, Acequión, Grajuela, Villar, Bonete, Casa Munibáñez y Barrax. Así lo recordaban varios vecinos interrogados a propósito de un litigio por la propiedad que se conserva en el Archivo de la Real Chancillería de Granada. El expediente carece de fecha, pero

${ }^{1}$ Topónimo estudiado por Pacheco Paniagua, J. A., García Sanchez, J.J., CELDRÁN, Pancracio y Pocklington, Robert (especificados en la bibliografía). 
por el tipo de letra lo podemos datar en el siglo $\mathrm{XV}^{2}$. En este documento los testigos confirman que desde tiempo inmemorial don Juan Manuel había hecho donaciones de tierras. Un testigo dice que oyó decir a su padre, y este a su suegro de ochenta años, que el infante hizo donación de tierra a vecinos de Chinchilla «para que se poblase de mucha parte de los términos».

Recordemos cómo se segregó Chinchilla de Alarcón para comprender los derechos sobre este vasto y a veces difuso término:

En 1269 le fue otorgado un término de forma irregular, obtenido mediante la división aritmética de la distancia que la separaba de otras cabeceras de concejo. Con Alcaraz y Alarcón, villas ya antiguas y bien pobladas, se dividió por la mitad, aunque con notable imprecisión, que daría lugar a fricciones posteriores, sobre todo en el que luego se llamaría Campo de Barrax (Pretel, 1992, p. 41).

Las donaciones fueron constantes en todo el siglo XV y una fuente de conflictos entre los propios vecinos de Chinchilla porque los no agraciados dudaban de su legitimidad en tanto no habían sido favorecidos. En el año 1489 el concejo acordó anular las realizadas en el «campo de Barrax»3. Y es precisamente esta locución la que nos interesa resaltar, porque de esta forma aparecerá escrito a lo largo de los siglos XV y XVI lo que hoy conocemos como Barrax.

En 1415 cuando se adjudica término a Albacete se menciona de este modo «del lugar de la Gyneta fasa el canpo que disen de varrax»4. La preposición fasa > 'hacia' introduce una orientación geográfica, pero no un camino hacia un lugar concreto, sino que se refiere a ese campo indeterminado y despoblado cuya característica es su improductividad. El campo de Barrax no tenía límites concre-

\footnotetext{
2 ARCHGR. Signatura 14.002, 11. Probanza sobre los repartimientos en Casa Alcaide, Acequión, Grajuela, Villar, Barrax, Bonete y Casa Munibáñez a vecinos de Chinchilla. Es posible que este documento permita adelantar las fechas del poblamiento de Barrax en un siglo. Recordemos que Aurelio Pretel estableció el final de la centuria del XV para tal hecho (2000, p. 77).

${ }^{3}$ AHPAB. Signatura 4.494, 1 .

${ }^{4}$ AHPAB. Signatura 4.536.
} 
tos, sino que era toda una comarca en la que los pueblos limítrofes, Chinchilla, Alcaraz y también Villarrobledo, según Aurelio Pretel, se afanaban en asentar pobladores en ese espacio cubierto de atochales, romerales o espartales que hubo que rozar para la producción cerealista con el fin de aumentar propiedades y vecindades, pero también para asegurarse la cosecha de trigo. Sin olvidarnos de otra fuente de recursos como los pastos para los ganados y las losas como abrevaderos.

\section{LA ETIMOLOGÍA DEL NOMBRE. TOPÓNIMOS DE BARRAX}

El término de Barrax no es exclusivo de la provincia de Albacete, en Vélez Blanco (Granada) existe un paraje con este nombre que, además, presenta coincidencias en cuanto a origen al haber sido una tierra de lentiscar, atochar o chaparral, donada en 1601 a don Juan Fajardo en el contexto conflictivo de los moriscos contra los cristianos viejos ${ }^{5}$.

La mayoría de los topónimos que encontramos en aldeas y parajes de Barrax son posteriores a la reconquista de este territorio. Apenas tiene dificultad intuir cual fue la motivación que llevó a nombres como El Romeral, Espartosilla, Las Encebras, Encebreros, La Coscoja, Hondoneros (hondonada del terreno), Losa Picada, Cerros Verdes, Cañada Blanca. En estos dos últimos casos el color se manifiesta como una característica apreciada en el paisaje, visible y llamativa, ambos colores son de los más abundantes en los topónimos de España, el adjetivo 'blanca' nos da otra pista que corrobora nuestra teoría de que la repoblación, tras la reconquista de esta zona en el siglo XIII, partía de cero, y es que en territorios más antiguos era utilizado el término latino albus, por el contrario, 'blanco' es ya romance (García, 2007, p. 259).

\footnotetext{
${ }^{5}$ http://www.velezblanco.es/Servicios/cmsdipro/index.nsf/informacion.xsp?p= VelezBlanco\&documentId=98054329DF86AE59C1257F5B004B1108 . Consulta [21/09/2021].
} 
Son, en todo caso, topónimos sencillos; sin embargo, Barrax no lo es, y, por ello, precisa de un esclarecimiento. Todo nombre actual, aunque nos parezca inexplicable, tuvo para sus hablantes un significado claro. El paso del tiempo y la evolución fonética o semántica los han ocultado.

Si todos los topónimos arriba enunciados son palabras romances y el propio municipio de Barrax no existe con anterioridad al siglo XIII, la razón de su etimología no puede buscarse en orígenes árabes que se pierden en la noche de los tiempos, como la «famosa venta» de Barraj', -que aparece por primera vez en 1894 en la obra Crónica de la provincia de Albacete de Roa Erostarbe y que sigue copiando y perpetuando -sin contrastar- todo aquel que publica algo en papel o en la Web sobre el municipio-, sino en algo cotidiano y visible que fuera característico de esta zona. Por eso tras consultar varios diccionarios etimológicos, actuales y antiguos, a los que hemos sumado la bibliografía al respecto y los documentos más antiguos de los archivos ${ }^{7}$, pensamos que Barrax debe hacer referencia al campo, la misma raíz barr- en el diccionario de Sebastián Covarrubias (el más antiguo y por lo tanto más próximo a los hablantes de aquella época, publicado en 1611) aparece como arábiga, con significado de «campo», pero en el sentido de campo inculto, que no se labra, de ahí 'barro' -prosigue el Diccionario- tierra mezclada con agua (pero tierra sin cultivar) y 'barrizal', lugar muy húmedo o encharcado.

El «campo de Barrax» corresponde a una tautología definida como:

Repeticiones de una misma noción expresada de distintas maneras, se suele deber a la llegada de hablantes de una nueva lengua que desconocen el significado del apelativo que dio lugar al topó-

\footnotetext{
${ }^{6}$ https://es.wikipedia.org/wiki/Barrax. [Consulta 19/09/2021].

7 Dos documentos emanados de la Cancillería Real (AHPAB, signatura 4.515, expediente 15 y Archivo General de Simancas, LEG, 150006,106) mencionan el «campo de varax» con una sola -«r», frente a otros dos (AHPAB, signatura 4.536 y 4.574) en los que aparece con doble consonante el «campo de Barrax». Uno del archivo de la Real Chancillería de Granada, Signatura 14.002, 11 que repite locución.
} 
nimo inicial, correspondiente a la lengua hablada anteriormente en ese territorio; por eso muchos topónimos tautológicos son híbridos [...] (García, 2007, p. 307).

Un buen ejemplo sería Valle de Arán -Val d'Aran- 'valle del valle', pues aran en vaso significa 'valle' (García, 2007, pp. 307, 201). En nuestro caso nos hallamos ante un topónimo de origen árabe pero incorporado al léxico romance, y, totalmente acertado para definir ese campo sin cultivar y de límites difusos, disputado por todos los concejos que lo rodeaban para asentar población y aumentar sus cultivos y pastos.

Faltaría la explicación de la terminación - $a x$, o $-a j$, como a veces también aparece en los documentos antiguos ('Barraj'), terminación consonántica no habitual en la lengua castellana, que nos remite otra vez a su origen árabe. «El resultado final $-x$ se debe a una de las adaptaciones del árabe $\hat{y}$-del que también ternemos como resultado, con la evolución propia del idioma, esp. $j$. Ese final $-x$ puede ser también reflejo de la pronunciación árabe [š] adoptada a partir de una $s$ romance». Ejemplos en castellano tenemos: Almorox $(<$ ar. Al-muruŷ 'los prados'), Guadix, Torrox, Darrax, Borox... (García, 2007: 344).

\section{CONCLUSIÓN}

Por todo lo anteriormente expuesto nuestra hipótesis se decanta por la definición que contiene el diccionario de Covarrubias para explicar la raíz de Barrax, barr-, 'campo inculto', porque se identifica con el contexto histórico en el que surge la población, ese campo improductivo y sin delimitar nítidamente en su origen que reflejan los documentos más antiguos con la expresión «campo de Barrax», expresión que aun utilizan los agricultores en la actualidad, al menos los de más edad. 


\section{REFERENCIAS BIBLIOGRÁFICAS}

CELDRÁN, P. (2009): Diccionario de topónimos españoles y sus gentilicios. Espasa-Calpe.

COROMINAS, J. (2012): Diccionario crítico etimológico castellano e hispánico. Gredos. CD-ROM.

COVARRUBIAS OROZCO, S. (1611): Tesoro de la lengua castellana $o$ española. En: www.cervantesvirtual.com/obra-visor/delorigen-y-principio-de-la-lengua-castellana-o-romance-queoy-se-vsa-en-espana-compuesto-por-el--0/html/ [consulta 03/10/2021].

GARCIA SANCHEZ, J. J. (2007): Atlas toponímico de España. La Muralla.

PACHECO PANIAGUA, J. A. (1979): Sobre la etimología de Albacete. Albasit, (6), 70-78.

POCKLINGTON, R. (2010): Toponimia ibérica, latina y árabe de la provincia de Albacete. Albasit, (55), 111-167.

PRETEL MARÍN, A. (1992): Chinchilla medieval. Instituto de Estudios Albacetenses «Don Juan Manuel».

PRETEL MARÍN, A. (2000): Iglesia, religión y religiosidad en la Baja Edad Media albacetense. Albasit, (44), 45-109.

ROA EROSTARBE, J. (1894): Crónica de la provincia de Albacete. Imp. y Encuadernación de la viuda de J. Collado. 